\title{
Volatility Estimation Using Symmetric and Asymmetric Models in Oil Exporting Emerging Markets
}

\author{
Dr Latha Sreeram \\ Professor, Dept of Finance \\ GNVS Institute of Management, India
}

Tel: 91-98-3360-9896Ｅ-mail: lathamurthy9500@gmail.com

\author{
Received: Jan. 9, 2019 Accepted: Feb. 24, $2019 \quad$ Published: June 1, 2019 \\ doi:10.5296/ajfa.v11i1.14202ＵRL: https://doi.org/10.5296/ajfa.v11i1.14202
}

\begin{abstract}
The study empirically investigates the volatility pattern of thirteen emerging economies which are predominantly oil exporting countries. It is based on the time series data which consists of monthly closing price data of their index for a ten-year period from 01 January 2008 to 31 December 2017. Emerging markets are considered as investment destinations due to the presence of risk premium which has made the stock markets of these countries more volatile. Added to this is that these countries underwent crisis due to the sharp decline in crude oil prices as they were primarily dependent on oil exports. Hence it is a significant to study the volatility behavior of these countries. The study has been done by employing both symmetric and asymmetric models of generalized autoregressive conditional heteroscedastic. As per Akaike Information Criterion (AIC), Log likelihood and Schwarz Information Criterion (SIC) the study provides evidence that GARCH $(1,1)$ and TGARCH$(1,1)$ estimations are found to be the most appropriate model that fits symmetric and asymmetric volatility respectively for all the thirteen countries. There was evidence of volatility clustering and leptokurtic in all the countries considered in the study. While EGARCH model revealed no support of existence of leverage on the stock returns, TGARCH supported existence of leverage in case of four countries. The tests for asymmetries in volatility indicate the size effect of the news, reaffirmed through the results of sign bias tests and news impact curves, which indicate that the size effect is stronger for bad news than the good news for countries which supported existence of leverage.
\end{abstract}

Keywords: Volatility Modeling, Emerging Markets, GARCH, Leverage, Heterosedascity, Asymmetry, NIC curves

JEL Classification Codes: C5, C22, C53, G1, G10, G15 


\section{Introduction}

Some of the most accepted univariate conditional volatility models are the Generalized Autoregressive Conditional Heteroscedasticity (GARCH), Glosten, Jagannathan and Runkle (GJR), Threshold GARCH Model (TGARCH) and Exponential GARCH (EGARCH) model. These models estimate and forecast volatility and also indicate asymmetry, which implies that they capture different effects on conditional volatility of positive and negative effects of equal magnitude. They indicate the presence of leverage which is the negative correlation between the shocks to returns and subsequent shocks to volatility.

Stock Market volatility is a well-researched topic as per the evidence of the empirical literatures; this paper investigates the possibility to explore new information on volatility pattern using the extended GARCH models. The data taken is from the monthly closing data of thirteen emerging markets chosen on the basis of their listing as Emerging economies and are primarily oil exporting countries. Hence the data analyzed is from the year 2007 to 2016 considering a total period of ten years to estimate the volatility of the countries considered for this study. Global crude oil prices have witnessed a steady decline by 103\% from 2012 to 2016 leading to a remarkable revenue deficit in many crude oil exporting nations. The substantial supply of crude oil by the oil producing countries during the period continued to pressure markets. The Volatility in crude oil prices has had an extensive impact on the economy as well as the stock market of oil exporting countries; specially emerging economies. This study seeks to find the volatility in the stock markets of these oil exporting, emerging economies during that phase.

\section{Review of Literature and development of hypothesis}

In the past decades, Economists have captured the transformation in financial data. Fitting an estimated model for volatility has been the intent for researchers viz. French, Schwert and Stambaugh (1987), Bollerslev (1987), Engle (2002). Much of the research on modeling the volatility shares the asymmetries found in stock market returns. Engle and $\mathrm{Ng}$ (1993) substantiated the Quadratic- GARCH model with evidence. Brailsford and Fagg (1996) confirmed that GJR-GARCH was most suitable; Heynen and Kat (1994) established that EGARCH has a finer extrapolative ability. Even though the literature does not prove any one individual asymmetry model as being evidently better, Awartani and Corradi (2005) argue that they by and large do better than non-asymmetric models in financial market prediction. However, McMillan, Speight and Apgwilym (2000) established that GARCH, moving average and exponential smoothing models provided better daily volatility forecasts and specifically EGARCH does not essentially surpass simple GARCH model.

Brooks (2007) examined a set of markets using the Asymmetric Power ARCH model. He established that in the developed markets, non-normal conditional error distribution fit the data accurately and in case of emerging markets where estimation problems arise a conditional ' $t$ ' distribution fits better. Further the degree of volatility asymmetry differs across markets, with the Middle Eastern and African markets having very different volatility asymmetry characteristics compared to Latin American markets. Raza et al. (2015) applied a number of GARCH family models for the valuation and foreseeing the volatility of KSE100 Index stock returns. The results indicated that the best-fitted volatility model was $\operatorname{GARCH}(1,1)$ with 
students t-distribution and best prediction volatility model is $\operatorname{GARCH}(1,1)$ with GED, and the next fit volatility forecasting model is EGARCH $(1,1)$ with GED. Su (2010) empirical study found that the EGARCH model fits the sample data better than GARCH in modeling the volatility of Chinese stock returns. Tuyen (2011) investigated whether the stock return volatility vary over time in Vietnamese stock market and found that the standard GARCH model was well fit. Floros (2008) examined the use of GARCH -type models for modeling volatility in Egypt (CMA General index) and Israel (TASE - 100 index). His results proved that the daily returns can be characterized by the GARCH models. Abd El Aal (2011) examined Egyptian stock market return volatility and he found that EGARCH is the best fit model.

Some of the research which applied ARCH/GARCH models on emerging stock markets to estimate and predict volatility found the occurrence of non-normality, volatility clusters, negative skewness, leptokurtosis such as the studies of Aydin (2002), Akgul and Sayyan (2005) and Gokbulut and Pekkkaya (2014), Rashid and Ahmad (2008) \& Goudarzi and Ramnarayanan (2011). Gokbulut and Pekkaya (2014) maintained that the CGARCH and TGARCH were finer in modeling volatility. Floros (2008) and Emenike (2010) in Nigeria, Su (2010) in China, Angabini and Wasiuzzaman (2011) in Malaysia, Abd el Aal (2011) and Ezzat (2012) in Egypt and Freedi et al. (2012) in Saudi Arabia applied TGARCH, EGARCH, and GJR GARCH models in their study and their findings indicated that EGARCH and GJR-GARCH are the best models for measuring volatility, detecting clustering effect, leptokurtosis and the leverage effect. This study forms the first hypothesis as:

\section{H0:- Asymmetric information impacts more on the volatility of Emerging markets and an asymmetric model fits the return series well}

Historical examination of financial time series data has revealed that volatility is not constant over time (Mandelbrot, 1963). It has been found that great returns are frequently followed by further large returns and vice-a-versa termed as volatility clustering (Mandelbrot, 1963; Schwert and Seguin, 1990). The swing in volatility over time is due to the supposed market and unique risks not being constant, leading to risk at different periods. (Brooks, 2014). Further on, Asset returns have leptokurtic unconditional distributions (Mandelbrot 1963, Fama 1963, Fama 1965), which is related to the time varying volatility (Corhay and Rad, 1994) and are characterized by volatility clustering (Mandelbrot 1963, Fama 1965). Schwart (1989), proved that financial time series reveals high and low volatility episodes at any time, entailing that volatility in current time will lead to the probability of volatility many periods in future. Skewness can be associated to the fact that stock prices are liable to cluster; large (small) changes are followed by large (small) changes (Bollerslev 1987, Lo 2000). The next hypothesis in this study is:

\section{H0:- The monthly return data of the index are not normally distributed and that the series of residuals will exhibit conditional heteroscedasticity (ARCH effects)}

Shin (2005) studied the relationship between risk and return for numerous emerging markets and found a significant association between volatility and returns in emerging capital markets by following non-parametric conditional variance modeling. De Santis and Imrohoroglu (1997) examined stock returns and volatility in emerging markets and proved the presence of 
clustering, predictability and persistence in conditional volatility, but exhibit it at a higher level than mature markets. Bekaert and Harvey (1995) suggested that emerging markets are found to offer superior return than those of mature markets but is associated, nevertheless, with high volatility and high serial correlation. Lee C.F, Chen G.M and Rui O.M (2001) studied the financial data of stock returns and volatility in four of China's stock markets and found evidence of time-varying volatility and showed volatility is highly persistent and expected.

Balaban .E, Bayar .A and Fatt .R (2003) examined financial data from 14 countries and found ARCH-type models provide the best fitted model. Ogum .G, Beer .F and Nouyrigat .G (2005) investigated the market volatility using Nigeria and Kenya stock return series and found that the EGARCH model was the best fit and showed that asymmetric volatility found in the U.S. and other developed markets was also present in the Nigerian stock market (NSM), but Kenya demonstrated significant and positive asymmetric volatility. Based on the above literature the final hypothesis of this study is:

\section{H0: Stock Markets in the Emerging economies are volatile and persistent}

The ARCH and GARCH literature in emerging markets which are also primarily Oil exporting countries is very scarce. Hence an attempt is made in this study to explore the volatility pattern of the stock market in emerging economies which are primarily Oil exporting countries using both symmetric and asymmetric models. This study also investigates the presence of leverage effect in the daily return series using EGARCH and TGARCH model.

\section{Methodology}

\subsection{Data and Samples}

Monthly Close level data for analysis was extracted for selected emerging economies from January 2008 to December 2017.The data collected were transformed into continuously compounded return as follows:

$$
r_{t}=\operatorname{In}\left(P_{t} / P_{t-1}\right)^{*} 100
$$

$r_{t}=$ Logarithmic Index return, In $=$ Natural Logarithm, $P_{t}=$ Current closing price, $P_{t-1}=$ Previous closing price.

The indices considered are shown in Table No I, for the period covering January 1st, 2008 to December 31, 2017. After filtering the return series with AR (1) models, the study fitted the GARCH (1,1), TGARCH $(1,1)$, EGARCH(1,1), and GJR-GARCH(1,1) models with standardized Student ' $t$ ' model. Three methods are used to compare the models. The first one uses the Log likelihood, Akaike Information Criterion (AIC) (Akaike, 1974) and the Schwartz Information Criterion (SIC) (Schwarz, 1978) to select the best model. 
Table I. Name of the Exchange

\begin{tabular}{|c|c|c|c|c|}
\hline Country & Name of Exchange & Index & Year of Establishment & $\begin{array}{l}\text { No of listed } \\
\text { Companies }\end{array}$ \\
\hline South Africa & Johannesburg Stock exchange & JSE & 8th November 1887 & 388 \\
\hline South Korea & Korean Exchange & KRX & 27th January 2005 & 2030 \\
\hline $\begin{array}{l}\text { Saudi } \\
\text { Arabia }\end{array}$ & Tadawul & TASI & 19th March,2007 & 171 \\
\hline Peru & The Lima Stock Exchange & BVL & 31st December, 1860 & 283 \\
\hline Hungary & Budapest stock Exchange & BSE & 18th January, 1864 & 58 \\
\hline Iran & Tehran Stock Exchange & TSE & February 4, 1967 & 339 \\
\hline Brazil & Brasil Bolsa Balcão S.A.(B3) & BOVESPA & August 23,1890 & 368 \\
\hline Poland & Warsaw Stock Exchange & WSE & April 12, 1991 & 64 \\
\hline Philippines & Philippine Stock Exchange & PSE & August 8, 1927 & 344 \\
\hline Vietnam & $\begin{array}{l}\text { Ho Chi Minh City Stock } \\
\text { Exchange }\end{array}$ & HOSE/HSX & July,2000 & 396 \\
\hline Columbia & Colombia Stock Exchange & BVC & November 23,1928 & 89 \\
\hline Russia & Moscow Exchange & MOEX & 19 December 2011 & 219 \\
\hline Egypt & Egyptian Exchange & EGX & March, 1883 & 202 \\
\hline
\end{tabular}

\subsection{Stationarity Test}

The financial time series data is deemed stationary, when it's mean, variance and autocovariance at different lags are same and so time independent. For a stationary series, shocks to the data die away steadily. If the impact of the shocks to the system persists for a longer period, the system will be explosive. Any research on non-stationary data leads to spurious regression. The study used Philips-Peron unit root test on the data for determination of stationarity.

The test involves fitting the regression as:

$$
Y_{t}=\alpha+P Y_{t-1}+e_{i}
$$

\subsection{Testing for ARCH Effects}

The Indices were tested by using Box and Jenkins (1976) methodology and Ljung-Box (1978) to determine the number of Autoregressive (AR), Moving Average (MA) and ARMA terms. 


\subsubsection{Box and Jenkins (1976) Methodology}

Box-Jenkins (1976) methodology involves three steps: -

1. Detection of AR/MA/ ARMA and ARIMA order by correlogram and partial correlogram (lags 1 to 30).

2. Assessment of the parameters (co-efficient) of the AR/MA/ARMA and ARIMA model.

3. Diagnostic Checking of the selected AR/MA/ARMA/ARIMA model.

$$
\begin{gathered}
\mathrm{AC} \text { at K lags }\left(\rho_{k}\right)=\mathrm{Cov} u_{t}, u_{t-k} / \sqrt{V A R U_{t}} \mathrm{X} \sqrt{ } V A R U_{t-k} \\
\mathrm{PAC} \text { at } \operatorname{lag} 1=\mathrm{AC} \text { at lag } 1=\left(\rho_{11}-\rho_{1}^{2}\right) \\
\mathrm{PAC} \text { at } \operatorname{lag} 2\left(\rho_{22}\right)=\left(\rho_{2-\rho_{1}^{2}}\right) /\left(1-\rho_{1}^{2}\right)
\end{gathered}
$$

The study then used the ACs and PACs by plotting them graphically to obtain the correlogram. This enabled in the determination of AR/MA/ARMA model. For using Box-Jenkins's methodology, to accurately determine the AR/MA/ARMA terms, OLS regression is run on $\mathrm{Yt}$ with Yt-I and ut-1. The significance of regression coefficients of lagged term the values of Akaike's Information Criteria (AIC) and Schwarz's Bayesian Information Criteria (SBIC) are used.

$$
\begin{aligned}
& \text { AIC value }=\left[\operatorname { I n } \left(\begin{array}{ll}
\sum_{t=1}^{T} & \left.\left.u_{t}^{2}\right)\right]+2 \mathrm{k} \\
\mathrm{SBIC} \text { value }=\mathrm{T}\left[\operatorname{In}\left(\sum_{t=1}^{T} u_{t}^{2}\right)\right]+\mathrm{K} \operatorname{In}(\mathrm{T})
\end{array}\right.\right.
\end{aligned}
$$

$\mathrm{K}=$ No. of parameters to be estimated

$\mathrm{T}=$ total No. of Observations

$\ln =$ Natural logarithm

\subsubsection{Ljung-Box (1978) Test}

The test of significance for the values of (AC) and (PAC) are computed by using the QStatistics proved by Ljung-Box (1978), which is as follows:

$$
Q_{m}=\mathrm{T}(\mathrm{T}+2) \sum_{i=1}^{m} \rho_{1}^{2} / \mathrm{m}-1^{\sim} x_{m}^{2}
$$

Qm = Ljung-Box Q statistics

$\mathrm{T}=$ No. of observations

$\mathrm{i}=$ No. of lags varies from $1,2, \ldots \ldots, \mathrm{m}$.

$\rho_{m}^{2}=$ Sample ac at lag $\mathrm{m}$

$X_{m}^{2}=$ chi-square distribution ' $\mathrm{m}$ ' degrees of freedom 


\section{Macrothink}

The test is used to check the soundness of autoregressive conditional heteroscedasticity (ARCH) in the residuals. The return series demonstrate the presence or absence of ARCH effect heteroscedasticity, which is a precondition for applying the GARCH models to the return series. Hence the next step would be volatility modeling using GARCH models.

\subsection{Heteroscedasticity Test}

Heteroscedasticity is the unequal variance $\left(\sigma_{t}^{2}\right)$ in the error term $\left(u_{t}\right)$ obtained from the regression of Yt with Yt-I under OLS method. If coefficient of Yt-1 is statistically significant, it signifies the presence of autocorrelation in the return series between Yt and Yt-1. Hence before applying the GARCH methodology, the study examined the residuals to check the presence of heteroscedasticity. To this end, Lagrange multiplier (LM) test for ARCH has been used, against the null hypothesis of no arch effects. The statistic has a Chi-square distribution with ' $q$ ' degrees of freedom. If the LM statistic is larger than the critical value, then there is evidence of presence of ARCH effects.

\subsection{Lagrange Multiplier Test}

The LM is a test for ARCH in the residuals. The ARCH-LM test statistic is calculated from a supplementary test regression. The test procedure is executed by first finding the residuals $\varepsilon_{t}$ from the OLS regression of the conditional mean equation which might be a an autoregressive process, moving average process or a combination of AR and MA process (ARMA) (Suliman 2012). In this study, an ARMA (1,1) model for the conditional mean in the return series is used as a supplementary regression. The conditional mean equation is:

$$
R_{t}=\emptyset_{1} R_{t-1}+\varepsilon_{t}+\emptyset_{1} \varepsilon_{t-1}
$$

The objective is to obtain the residuals from the regression in order to test the null hypothesis that there is no ARCH up to order ' $\mathrm{q}$ ' in the residuals. To test the null hypothesis a regression is run as follows:

$$
\varepsilon_{t}^{2}=\alpha_{0}+\alpha_{1} \varepsilon_{t-1}^{2}+\alpha_{2} \varepsilon_{t-2}^{2}+\ldots . .+\alpha_{q \varepsilon_{t-q}^{2}}+V_{t}
$$

The null hypothesis that all 'q' lags of the squared residuals have coefficient values that is not significantly different from zero. If the value of the test statistic is larger than the critical values from the $\chi^{2}$ distribution, then the null hypothesis would be rejected.

\subsection{Student-t Distribution Assumption}

This was employed to report for fat tails that are common in financial series. The ARCH models are estimated by applying the maximum likelihood approach given a distributional assumption. The contribution to the likelihood for observation ' $t$ ' for the student- $t$ distribution is as follows:

$$
i_{t}=\frac{1}{2} \log \left(\frac{\pi(v-2) r\left(\frac{1}{2}\right)^{\wedge} 2}{r \frac{(v+1)^{\wedge} 2}{2}}-\frac{1}{2} \log \sigma_{t}^{2}-\frac{v+1}{2} \log \left(1+\frac{y_{t-x} t \theta^{\wedge} 2}{\sigma_{t}^{2}(v-2)}\right.\right.
$$


Where $\mathrm{r}$ (.) is a gamma function and $\mathrm{v}>2$ is a shape parameter which controls the tail behavior. Thus when $\mathrm{v} \rightarrow \varphi$, the distribution converges to Gaussian.

\subsection{Mean Reversion}

Mean reversion implies that the present information has no influence on the long run forecast of the volatility. Persistence dynamics in volatility is generally captured in the GARCH coefficients of the GARCH model. In the stationery GARCH model, the volatility mean reverts to its long run level, at a rate given by the sum of $\mathrm{ARCH}$ and GARCH coefficients which is usually closer to 1 . The magnitude of the mean reverting rate $\alpha_{1}+\beta_{1}$ controls the speed of the mean reversion.

\subsection{Volatility Measurement Techniques}

\subsubsection{Symmetric Models}

Most of the studies endeavored on modeling volatility found that $\operatorname{GARCH}(1,1)$ is the best to capture the symmetric effects and for the leverage effects EGARCH model have been found to be appropriate by previous studies. The present study uses GARCH $(1,1)$, EGARCH and TGARCH to capture symmetric as well as asymmetric effects of the return series and to choose the most appropriate model in volatility estimation. To model leverage effects characteristics of the data the EGARCH and TGARCH models were used. According to Brook and Burke (2003) lag order $(1,1)$ is satisfactory to capture all the volatility clustering in the returns data. The GARCH model (Bollerslev, 1986), which allows the conditional variance to be dependent upon the previous own lags conform to the conditional variance equation in the simplest form as:

Mean equation: $r_{t}=\mu+e_{t}$ and

Variance equation: $\sigma_{t}^{2}=\omega+\alpha \varepsilon_{t-1}^{2}+\beta \varepsilon_{t-1}^{2}$

Where $\omega>0, \alpha_{1}, \beta_{1} \geq 0, r_{t}$ is the return of the asset at time t, $\mu$ is the average return and $\varepsilon_{t}$ is the residual return. The conditional variance equation postulates that the volatility in the current period is not only related to the squared error term in the previous term but also on its conditional variance in the previous time period.

\subsubsection{Asymmetric Measurement}

\section{EGARCH Model}

The key shortcoming of the symmetric GARCH is that the conditional variance is not capable of reacting asymmetrically to abrupt changes in the stock returns as only the squared residuals $\varepsilon_{t-1}^{2} \quad$ enter the equation and the signs of the residuals or the shocks have no effect. EGARCH and TGARCH are two of the asymmetric models used in this study to check the association between asymmetric volatility and the returns. A stylized fact of financial volatility is that negative shocks tend to have a larger impact on volatility than the positive shocks. The extended GARCH models calculate conditional variance in the incidence of asymmetric shocks and persistence of the shocks to the market. EGARCH is one of the extensions of the GARCH model which captures the asymmetric effect of news and the volatility. 


$$
\sigma_{t}^{2}=\alpha_{0}+\alpha_{1} \cup_{t-1}^{2}+\alpha_{2} \cup_{t-2}^{2}+\ldots \ldots \ldots \alpha_{p} \cup_{t-q}^{2} \ldots \ldots \ldots . . . A R C H(q)
$$

$\alpha 0=$ is the measure of long term constant volatility i.e. unconditional variance estimation.

$\alpha 1 \ldots \alpha q$ are the coefficients of the residuals/ error terms

$\alpha 1=$ is the measure of persistence

$$
\sigma_{t}^{2}=\alpha_{0}+\alpha_{1} \cup_{t-1}^{2}+\beta \sigma_{t-1}^{2}
$$

$\alpha 0, \alpha 1$ and $\beta 1$ are the coefficients of the regression

$\alpha 0$ unconditional variance estimation

$\alpha 1+\beta 1$ represents persistence

Equation given by Nelson (1991) for $\operatorname{EGARCH}(1,1)$

$$
\operatorname{In} \sigma_{t}^{2}=\omega+\beta_{1} \operatorname{In}\left(\sigma_{t-1}^{2}\right)+\alpha_{1}\left[\left(\left|\frac{e_{t-1}}{\sigma_{t-1}}\right|\right)-\sqrt{\frac{\pi}{2}}\right]-\gamma \frac{\varepsilon_{t-1}}{\sigma_{t-1}}
$$

The above equation gives the log of the conditional variance. The co-efficient $\gamma$ is the asymmetry term and the presence of leverage effects can also be tested by the hypothesis that $\gamma<0$.

\section{Threshold GARCH model-TGARCH}

The conditional variance for threshold GARCH (Zakoiian, 1994) is given by the following generalized specification:

$$
\sigma_{t}^{2}=\omega+\alpha_{1} \varepsilon_{t-1}^{2}+\gamma d_{t-1} \varepsilon_{t-1}^{2}+\beta \sigma_{t-1}^{2}
$$

The $\gamma$ coefficient captures the asymmetry in the return series if its value is positive. All the other variables in the equation other than the error term are the parameters of the conditional variance equation that will be estimated. In TGARCH model, the impact of good news $\left(\varepsilon_{t}>0\right)$ and bad news $\left(\varepsilon_{t}<0\right)$ on the conditional variance is different. When $\gamma$ is positive there is leverage effect and when it is not equal to 0 it is asymmetric. TGARCH presumes that the impact of the squared error term of the conditional standard deviation is dissimilar when the error term is positive or negative. As a result, it establishes a sign that takes the value of 0 when the conditional standard deviation is positive and 1 when negative. The leverage term usually occurs when the unconditional returns are skewed, ensuing in positive (negative) $\gamma$ approximation when the returns are negatively skewed on average.At times the magnitude or the size of the shock will also impact the response to volatility to shocks is symmetric or not. To investigate this negative sign bias has to be conducted and is present if $b_{1}$ is statistically significant in the following regression:

$$
Z_{i, t}^{2}=b_{0}+b_{i} D_{i, t-1} \varepsilon_{i, t-1}+v
$$




\section{Macrothink}

The positive sign bias is said to be present if $b_{1}$ is statistically significant in the regression given below

$$
Z_{i, t}^{2}=b_{0}+b_{i}\left(1-D_{i, t-1}\right) \varepsilon_{i, t-1}+v
$$

\section{Estimation Results}

\subsection{Descriptive Statistics}

Table II presents the descriptive statistics of the Emerging economies which is the continuously compounded monthly returns series over the period under the study. The data is negatively skewed for Saudi Arabia, South Korea, South Africa, Philippines, Russia and Colombia indicating that in these countries there is high probability of earnings return which is greater than the mean returns and the distribution of the variables has a long left tail. Further it implies that the distribution is negatively skewed to the normal distribution. The volatility is very high in emerging markets such as Iran, Saudi Arabia, Vietnam and Russia as measured by the standard deviation. This result of high volatility in emerging markets is consistent with Harvey (1995).

The Data is normally distributed when the results of the analysis for skewness are zero and kurtosis is three. The descriptive statistics (Table II) of the return data over the period of study were derived by using R software. The normality test of the descriptive statistics was found by using an asymptotic Jarque-Bera (1981) test statistic which is:

$$
\text { JB statistics }=\mathrm{T}\left(\frac{S^{2}}{6}+\frac{(K-3)^{2}}{24}\right)
$$

$\mathrm{T}=$ No. of observations

$\mathrm{S}=$ Skewness coefficient

$\mathrm{K}=$ Kurtosis coefficient

JB test of normality is the test of the joint null hypothesis if S \& $\mathrm{K}$ are 0 and 3, correspondingly. The kurtosis is greater than 3 in case of South Korea, Iran, Colombia, Philippines, Peru and Hungary; implying that the return series is fat tailed. This is further confirmed by the JB statistics which is significant at $1 \%$ level. The hypothesis of monthly return series being not normally distributed is accepted. 
Table II. Descriptive

\begin{tabular}{|l|l|l|l|l|l|}
\hline $\begin{array}{l}\text { Name of the } \\
\text { Country }\end{array}$ & Mean & Median & $\begin{array}{l}\text { Standard } \\
\text { Deviation }\end{array}$ & Skew & J-B \\
\hline Brazil & 0.0093 & 0.008 & 6.5 & 0.5735 & -0.1834 \\
\hline Poland & 0.007 & 0.0064 & 5.6 & 0.0033 & -0.3088 \\
\hline Peru & 0.01544 & 0.0089 & 4.7 & 3.4712 & 0.3032 \\
\hline Hungary & 0.011 & 0.011 & 6.6 & 2.025 & -0.4334 \\
\hline Iran & 0.00013 & 0.0012 & 8.2 & 142.5 & 11.8798 \\
\hline S. Africa & 0.0109 & 0.0111 & 4.35 & -0.1586 & 0.7085 \\
\hline S. Korea & 0.0069 & 0.0073 & 5.11 & -0.4549 & 3.3637 \\
\hline S.Arabia & 0.057 & 0.0124 & 7.91 & -0.4098 & 0.6957 \\
\hline Philippines & 0.0118 & 0.0185 & 5.5 & -0.6096 & 2.4861 \\
\hline Vietnam & 0.0107 & 0.0034 & 9.4 & 1.9801 & 0.5504 \\
\hline Colombia & 0.0052 & 0.0101 & 4.01 & -0.7616 & 2.1783 \\
\hline Russia & 0.0123 & 0.01219 & 8.9 & -0.1891 & 1.5475 \\
\hline Egypt & 0.0199 & 0.0219 & 0.01019 & 0.2222 & 1.5000 \\
\hline
\end{tabular}

\subsection{Stationarity Tests}

Table III shows the presence of unit root in the series tested using PP tests. The results indicate that it has produced higher negative value than its critical value at $1 \%, 5 \%$ and $10 \%$ level and significant at $1 \%$ level. Hence we reject null hypothesis and accept that the returns are stationery for the entire study period and is mean reverting.

Table III. PP -Unit root test and Arch-LM test of Residual

\begin{tabular}{|c|c|c|c|c|c|c|c|c|c|c|c|c|c|}
\hline & Vietnam & Iran & Peru & Poland & Hungary & $\begin{array}{c}\text { South } \\
\text { Africa }\end{array}$ & $\begin{array}{c}\text { Philipp } \\
\text { ines }\end{array}$ & $\begin{array}{c}\text { South } \\
\text { Korea }\end{array}$ & $\begin{array}{c}\text { Saudi } \\
\text { Arabia }\end{array}$ & Colombia & Egypt & Brazil & Russia \\
\hline $\begin{array}{c}\text { PPTest } \\
\text { T- stat }\end{array}$ & -8.8328 & - & -11.69 & -11.703 & -10.491 & -13.216 & -11.897 & -11.362 & -10.548 & -10.734 & -8.84 & -13.582 & -11.027 \\
\hline Prob & 0.01 & 0.01 & 0.01 & 0.01 & 0.01 & 0.01 & 0.01 & 0.01 & 0.01 & 0.01 & 0.01 & 0.01 & 0.01 \\
\hline $\begin{array}{c}\text { Arch-LM } \\
\text { test }\end{array}$ & 28.364 & 0.051 & 20.989 & 28.268 & 12.645 & 25.653 & 17.584 & 51.135 & 26.731 & 18.078 & 23.82 & 19.63 & 39.544 \\
\hline \begin{tabular}{c} 
Prob(1) \\
\hline
\end{tabular} & 0.012 & 1 & 0.002 & 0.001 & 0.024 & 0 & 0.04 & 0 & 0 & 0 & 0.03 & 0.01 & 0 \\
\hline
\end{tabular}

\subsection{L-JUNG Box Tests and Testing for ARCH effects}

After the first step of obtaining the residuals $\varepsilon_{t}$, from the ARMA process ARCH LM test was applied to test for the presence of $\mathrm{ARCH}$ effect in the residuals by regressing the squared residuals on a constant and 5 lags. The output in table III shows that there are ARCH effects in the return series for all the countries. Thus the variance of the errors is non-constant for the period under the study. The series being stationery, the study proceeds with the determination of the best fitting mean equation by applying ARMA (auto regressive moving average) to 
choose the best process in modeling the conditional mean. Table IV depicts appropriate ARMA models, fitted by using BOX- Jenkins Methodology, for all the indices considered. Fitted ARMA models generally follow moving average pattern apart from Russia, Egypt, Poland and Hungary where autoregressive pattern are found along with the moving average pattern. But Saudi Arabia return series follows a pure AR pattern. From the results it is found that most of the emerging economies have longer moving average pattern thus leading to persistent shocks in the market over a period of time.

Table IV. Fitted Autoregressive Moving Average Model

\begin{tabular}{|l|l|l|l|l|l|l|l|l|l|l|l|l|l|}
\hline Russia & Egypt & Colombi & Vietnam & Philippi & Saudi & South & Iran & South & Poland & Hungary & Peru & Brazil \\
\hline AR(1) & AR(1) & MA(1) & MA(1) & MA(1) & AR(1) & MA(1) & MA(1) & MA(1) & AR(1) & AR(1) & AR(1) & MA(1) \\
\hline MA(1) & MA(1) & MA(2) & MA(2) & MA(13) & & MA(4) & & MA(8) & MA(1) & MA(2) & MA(1) & MA(6) \\
\hline MA(2) & MA(2) & MA(6) & MA(6) & MA(16) & & MA(6) & & MA(11) & MA(2) & & & MA(9) \\
\hline & & MA(8) & MA(9) & & & & & & & & & MA(11) \\
\hline
\end{tabular}

\section{$4.4 \operatorname{GARCH}(1,1)$}

In this study we estimate conditional volatility using student's t distribution proposed by Bollerslev (1987) with $v$ greater than 2 degress of freedom. GARCH $(1,1)$ is applied on the selected emerging markets. The result of GARCH $(1,1)$ is shown in table V which disclose that parameter of GARCH is statistically significant. The coefficients constant $(\omega)$, ARCH term $\alpha$ and GARCH term $\beta$ are significant at $1 \%$ level. In the conditional variance equation, the estimated $\beta$ coefficient is to the highest degree greater than $\alpha$ coefficient which implies that the market has a memory longer than one period and the volatility is more responsive to its lagged values than its new surprises in the market values. Sampled parameters $\alpha, \beta$ are significant for all the markets other than Hungary as $\rho<0.01$ which signifies that the first lagged squared returns and the trailing variance significantly explains the conditional variance. The results confirms that the coefficient of the arch effects $\left(\alpha_{1)}\right)$ is statistically significant for all the countries except for Hungary, Brazil, Egypt and Philippines. This shows that the news from volatility of the previous period has an explanatory power on current volatility.

The summation of parameters $\alpha$ and $\beta$ establish the volatility in the return series and indicates that is persistent in case of all the countries. The sum of the coefficients is unity or closer to it indicating that the shock will persevere to many future periods. When the sum of the coefficients for market returns is closer to 1, the process of mean reversion gets slower (Engle 2001). The slowest mean reversion process is sighted in Brazil, Egypt, Saudi Arabia, South Korea, Poland and Iran. Hungary has the highest mean reversion process as the sum of coefficient is the least. With respect to $\operatorname{GARCH}(1,1)$ model it has been found that volatility is highly persistent for all the countries (sum of alpha and beta closer to unity) meaning a current shock persists indefinitely in conditioning the future variance. Hence large changes in the returns have a propensity to be followed by large changes and mild changes likely to be 


\section{Ml Macrothink}

Asian Journal of Finance \& Accounting ISSN 1946-052X 2019, Vol. 11, No. 1

followed by mild changes. It implies that in these countries stock returns volatility happens in clusters and is predictable.

The study applies GARCH $(1,1)$ consistent with many previous studies (Gokcan 2000). The parameters of GARCH model for the return series for all the countries is significant at $1 \%$ level, implying to reject the null hypothesis and accept the existence of volatility clustering in the return series. That is, volatility from the previous periods has the power of explaining the current volatility condition. Similarly the coefficient of the lagged conditional variance $\left(\beta_{1}\right)$ Is significantly different from zero indicating volatility clustering in the sample selected. Thus the return series for all the emerging economies have both the attributes- volatility clustering and are persistent. Hence all the tests indicate that variance equation is well characterized and specified. Further the ARCH-LM test is used to check ARCH effect residuals and from the results it is inferred that $\rho>0.05$. This proves that the variance equation is well specified for the market.

TABLE V. Estimated Result of S GARCH $(1,1)$ Model

\begin{tabular}{|c|c|c|c|c|c|c|c|c|c|c|c|c|c|}
\hline Mean & Egypt & Brazil & $\begin{array}{c}\text { Colom } \\
\text { bia }\end{array}$ & $\begin{array}{l}\text { Saudi } \\
\text { Arabia }\end{array}$ & $\begin{array}{l}\text { South } \\
\text { Korea }\end{array}$ & $\begin{array}{l}\text { South } \\
\text { Africa }\end{array}$ & Hungary & $\begin{array}{l}\text { Philip } \\
\text { pines }\end{array}$ & Russia & Vietnam & Peru & Poland & Iran \\
\hline$\mu($ constant $)$ & 0.020 & 0.010 & 0.01 & 0.01 & 0.003 & 0.01 & 0.01 & 0.01 & 0.01 & 0.01 & 0.02 & 0.01 & 0.00 \\
\hline $\mathrm{u}($ constant $)$ & 0.00 & 0.00 & 0.00 & 0.00 & 0.00 & 0.00 & 0.00 & 0.00 & 0.00 & 0.00 & 0.00 & 0.00 & 0.00 \\
\hline $\begin{array}{l}\alpha(\text { Arch } \\
\text { effects })\end{array}$ & 0.00 & 0.00 & 0.25 & 0.21 & 0.09 & 0.30 & 0.09 & 0.08 & 0.44 & 0.20 & 0.18 & 0.10 & 1.00 \\
\hline $\begin{array}{l}\mathrm{B} \text { (Garch } \\
\text { effects) }\end{array}$ & 1.00 & 1.00 & 0.69 & 0.79 & 0.90 & 0.63 & 0.76 & 0.87 & 0.51 & 0.75 & 0.77 & 0.87 & 0.00 \\
\hline$\alpha \pm \beta$ & 1.00 & 1.00 & 0.94 & 1.00 & 0.99 & 0.93 & 0.85 & 0.95 & 0.95 & 0.95 & 0.95 & 0.97 & 1.00 \\
\hline $\begin{array}{c}\log \\
\text { likelihood }\end{array}$ & 139.15 & 203.62 & 298.50 & 191.07 & 255.27 & 281.41 & 203.40 & 239.50 & 191.22 & 174.92 & 166.93 & 233.46 & 427.49 \\
\hline $\begin{array}{c}\text { Akaike } \\
\text { Information }\end{array}$ & -1.71 & -2.55 & -3.77 & -2.39 & -3.21 & -3.55 & -2.58 & -2.98 & -2.39 & -2.17 & -2.07 & -2.93 & -5.43 \\
\hline $\begin{array}{l}\text { Schwarz } \\
\text { Information }\end{array}$ & -1.72 & -2.55 & -3.78 & -2.39 & -3.22 & -3.43 & -2.58 & -2.99 & -2.39 & -2.18 & -2.08 & -2.93 & -5.44 \\
\hline $\begin{array}{c}\text { Arch-LM } \\
\text { test stat }\end{array}$ & 0.631 & 1.004 & 3.50 & 1.84 & 0.51 & 0.91 & 2.35 & 3.42 & 0.62 & 0.09 & 3.50 & 1.94 & 0.02 \\
\hline $\begin{array}{l}\text { Prob.chi } \\
\text { square(1) }\end{array}$ & 0.84 & 0.73 & 0.22 & 0.75 & 0.47 & 0.75 & 0.39 & 0.23 & 0.84 & 0.76 & 0.22 & 0.48 & 0.99 \\
\hline
\end{tabular}

\section{5 $\operatorname{EGARCH}(1,1)$}

In order to capture the availability of asymmetric behavior and the existence of leverage effect in the return series, the study applied EGARCH and TGARCH model. Table.VI represents the EGARCH output. The gamma parameter which is the indicator of asymmetric volatility is positive and significant at $1 \%$ level for Peru, South Africa, Iran and Colombia. This implies that shocks including both good and bad news will affect volatility for a long time in future and 
it is not expected to be forgotten within a short period of time. Further since the leverage coefficient being positive and significant, effect of previous period positive news is greater than effect of bad news of same magnitude. The Table also shows that ARCH $(\alpha)$ and GARCH coefficient $(\beta)$ are equal to one in case of Vietnam and Saudi Arabia and nearly to unity in case of other countries indicating that conditional variance is not explosive. Further coefficient gamma has specified the asymmetric effect as it is positive for all the countries in the study.

The asymmetric term in EGARCH is not negative and significant for any of the countries in the study suggesting that there is no leverage effects in the returns during the study period. This leads to the conclusion that previous period positive and negative shocks do not have a different impact on the conditional variance.

Iran, South Africa and Egypt markets are impacted due to recent information while South Korea, Vietnam and Saudi Arabia by old news or information. Iran has the highest leverage coefficient indicating that its stock market has been impacted by volatility due to negative information.

Findings show that sign-bias statistics are significant for the asymmetric models in case of Russia, Saudi Arabia and Vietnam. The two size bias test statistic is highly significant with positive size bias test statistic having higher value. This proves that size effect of news, is stronger for good news than bad news. Finally, ARCH LM test statistics discloses that the null hypothesis of no ARCH effects is accepted.

Table VI. Estimated Result of E GARCH $(1,1)$ Model

\begin{tabular}{|c|c|c|c|c|c|c|c|c|c|c|}
\hline Mean & Egypt & Brazil & $\begin{array}{c}\text { Saudi } \\
\text { Arabia }\end{array}$ & $\begin{array}{c}\text { South } \\
\text { Korea }\end{array}$ & $\begin{array}{c}\text { South } \\
\text { Africa }\end{array}$ & Philippines & Russia & Vietnam & Peru & Iran \\
\hline$\mu$ (constant) & 0.02 & 0.01 & 0.13 & 0.01 & 0.01 & 0.01 & 0.00 & 0.01 & 0.01 & 0.00 \\
\hline u(constant) & -1.00 & -0.85 & -0.18 & -0.15 & -0.95 & -0.66 & -0.69 & -0.17 & -0.49 & -8.15 \\
\hline $\begin{array}{c}\alpha \text { (Arch } \\
\text { effects) }\end{array}$ & -0.15 & -0.05 & -0.04 & 0.0 & -0.21 & -0.05 & -0.04 & -0.05 & -0.11 & -0.45 \\
\hline $\begin{array}{c}\text { B(Garch } \\
\text { effects) }\end{array}$ & 0.78 & 0.84 & 0.96 & 0.98 & 0.86 & 0.88 & 0.87 & 0.97 & 0.90 & -0.005 \\
\hline $\begin{array}{c}\text { gamma } \\
\text { gammen }\end{array}$ & 0.11 & 0.18 & 0.40 & 0.20 & 0.46 & 0.13 & 0.56 & 0.46 & 0.43 & 1.84 \\
\hline $\begin{array}{c}\text { shape } \\
\text { likelihood }\end{array}$ & 5.62 & 0.99 & 29.12 & 4.62 & 0.99 & 8.59 & 62.31 & 4.97 & 11.40 & 2.1 \\
\hline $\begin{array}{c}\text { Akaike } \\
\text { Information }\end{array}$ & -1.75 & -2.55 & -2.35 & -3.27 & -3.55 & -3.01 & -2.3 & -2.20 & -2.07 & -6.40 \\
\hline $\begin{array}{c}\text { Schwarz } \\
\text { Information } \\
\text { test Stat }\end{array}$ & -1.75 & -2.56 & -2.36 & -3.27 & -3.56 & -3.02 & -2.3 & -2.21 & -2.07 & -6.40 \\
\hline \begin{tabular}{c} 
Arch-LM \\
\hline
\end{tabular} & 1.64 & 2.42 & 0.18 & 0.56 & 2.69 & 3.18 & 0.65 & 0.63 & 1.14 & 0.01 \\
\hline
\end{tabular}




\begin{tabular}{|c|c|c|c|c|c|c|c|c|c|c|c|c|c|}
\hline Mean & Egypt & Brazil & $\begin{array}{c}\text { Colom } \\
\text { bia }\end{array}$ & $\begin{array}{l}\text { Saudi } \\
\text { Arabia }\end{array}$ & $\begin{array}{l}\text { South } \\
\text { Korea } \\
\end{array}$ & $\begin{array}{l}\text { South } \\
\text { Africa }\end{array}$ & Hungary & $\begin{array}{l}\text { Philip } \\
\text { pines }\end{array}$ & Russia & Vietnam & Peru & Poland & Iran \\
\hline$\mu($ constant $)$ & 0.02 & 0.01 & 0.00 & 0.01 & 0.00 & 0.01 & 0.01 & 0.01 & 0.01 & 0.00 & 0.00 & 0.00 & 0.01 \\
\hline $\mathrm{u}($ constant $)$ & 0.00 & 0.00 & 0.00 & 0.00 & 0.00 & 0.00 & 0.00 & 0.00 & 0.00 & 0.00 & 0.00 & 0.00 & 0.00 \\
\hline $\begin{array}{l}1 \text { (Arch } \\
\text { effects) }\end{array}$ & 0.00 & 0.00 & 0.00 & 0.23 & 0.06 & 0.16 & 0.00 & 0.00 & 0.36 & 0.29 & 0.00 & 0.03 & 0.24 \\
\hline $\begin{array}{c}\beta 1(\text { Garch } \\
\text { effects) }\end{array}$ & 1.00 & 1.00 & 0.74 & 0.79 & 0.93 & 0.61 & 0.83 & 0.77 & 0.48 & 0.76 & 0.80 & 0.80 & 0.92 \\
\hline gamma & -0.007 & -0.04 & 0.39 & -0.06 & 0.00 & 0.32 & 0.12 & 0.15 & 0.11 & -0.15 & 0.29 & 0.17 & 0.05 \\
\hline shape & 1.28 & 1.93 & 2.45 & 2.00 & 1.07 & 3.89 & 1.35 & 1.61 & 1.96 & 1.24 & 1.44 & 1.72 & 2 \\
\hline $\begin{array}{c}\text { Log } \\
\text { likelihood } \\
\end{array}$ & 143.223 & 204.67 & 303.62 & 191.224 & 262.76 & 286.77 & 209.01 & 239.83 & 190.38 & 180.12 & 172.97 & 235.31 & 538.91 \\
\hline $\begin{array}{c}\text { Akaike } \\
\text { Information }\end{array}$ & -1.74 & -2.54 & -3.81 & -2.36 & -3.28 & -3.59 & -2.62 & -2.99 & -2.35 & -2.22 & -2.12 & -2.93 & -6.87 \\
\hline $\begin{array}{c}\text { Schwarz } \\
\text { Information }\end{array}$ & -1.75 & -2.54 & -3.81 & -2.37 & -3.29 & -3.60 & -2.63 & -2.99 & -2.35 & -2.22 & -2.13 & -2.93 & -6.87 \\
\hline Arch-LM & 0.70 & 0.74 & 3.114 & 0.52 & 0.63 & 1.56 & 2.72 & 3.38 & 0.65 & 0.155 & 0.56 & 1.41 & 0.02 \\
\hline P-Value & 0.82 & 0.80 & 0.27 & 0.87 & 0.42 & 0.57 & 0.32 & 0.23 & 0.83 & 0.69 & 0.96 & 0.61 & 0.99 \\
\hline Prob & 0.55 & 0.38 & 0.96 & 0.45 & & 33 & 0.26 & 0.83 & 0.4 & & 0.69 & 0.99 & \\
\hline
\end{tabular}

\subsection{TGARCH $(1,1)$}

An alternate model to test for asymmetric volatility is TGARCH shown in Table VII. It has been found that coefficient of leverage effect is positive and significant at $1 \%$ level for Peru, South Africa, Iran, Colombia which implies that bad news or negative shocks have greater effect on conditional variance than positive shocks or good news. In other words, negative shock stimulates a larger raise in volatility greater than the positive shocks. It also implies that in these countries the distribution of the variance is skewed to the left and there are higher chances of negative returns. The positive asymmetric coefficient points out to the leverage effects in the above mentioned countries. The coefficient gamma in the model also established the asymmetric effect as it is positive for all the countries considered in the study and hence the hypothesis of asymmetry is accepted.

Table VII. Estimated Result of T GARCH $(1,1)$ Model

\subsection{News Impact Curves (NIC)}

NIC curves below presents the impact of news on volatility in the best fitted asymmetric models. The news Impact curves indicate that bad news have more impact on volatility than good news 


\section{Macrothink}

in Peru, Iran, South Africa, Colombia and Egypt. This is validated in the findings presented in Figure I. The graphs indicate that responsiveness of future volatility in stock returns vis-a-vis the current period news (shocks) and are determined from the residuals of the models.

The positive slope of the NIC of the symmetric models measures the level of confidence in the market. The upward trend of the NIC on the positive side of the shocks depicts increasing confidence in the stock markets of Russia, Saudi Arabia and Vietnam. This is an indication of a well fitted model and is similar to research findings of (AI,2011), (Eric 2008) and Hojatallah (2011). A positive return shock does not seem to have much impact on conditional volatility. In other words, when the stock market experiences a sharp decline, the large negative return shock leads to high volatility. When the market re-bounds the large positive returns does not seem to reduce the volatility immediately. Thus high volatility could not be reduced quickly with large positive return shocks and there is high persistence as per the results of the study. 

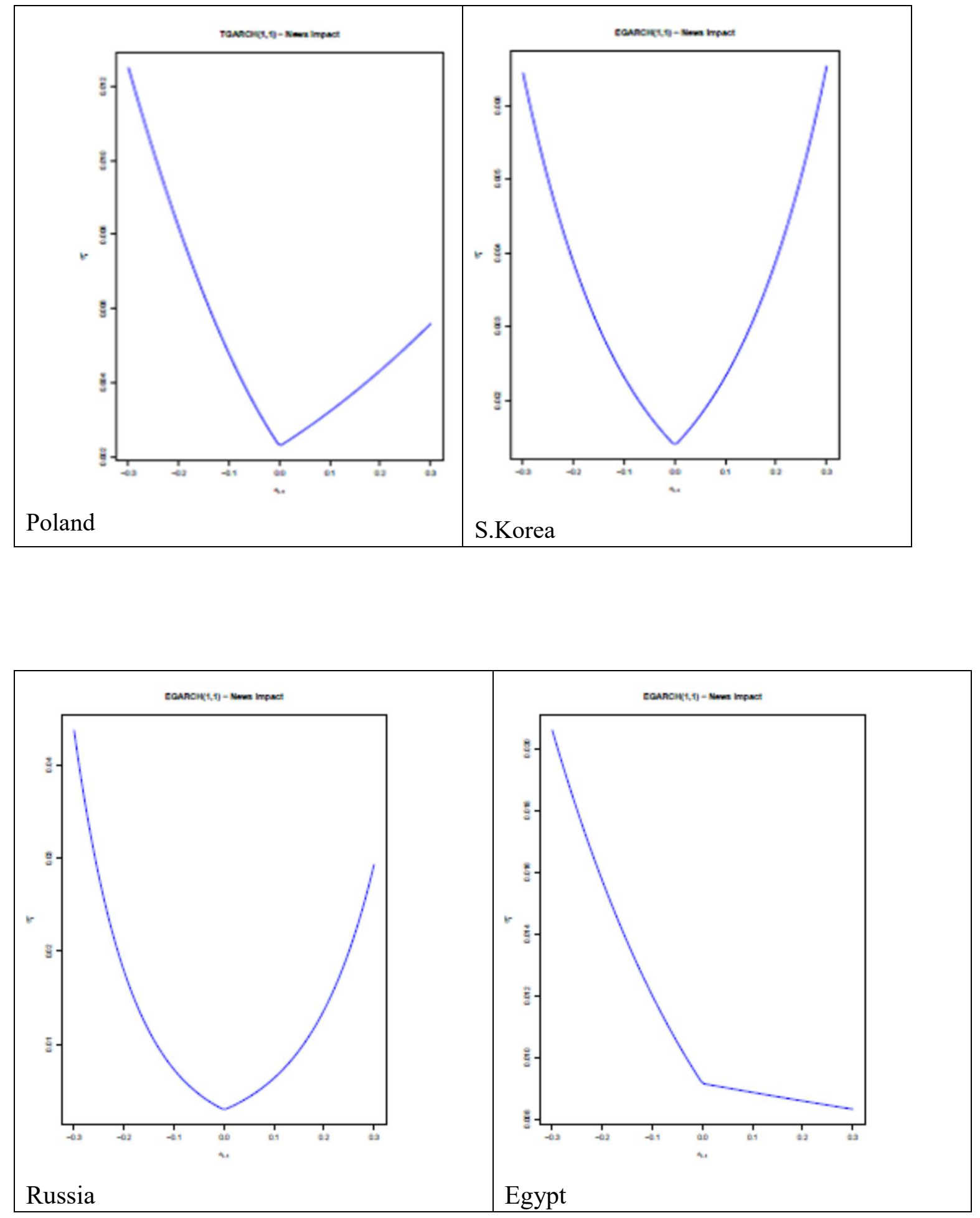

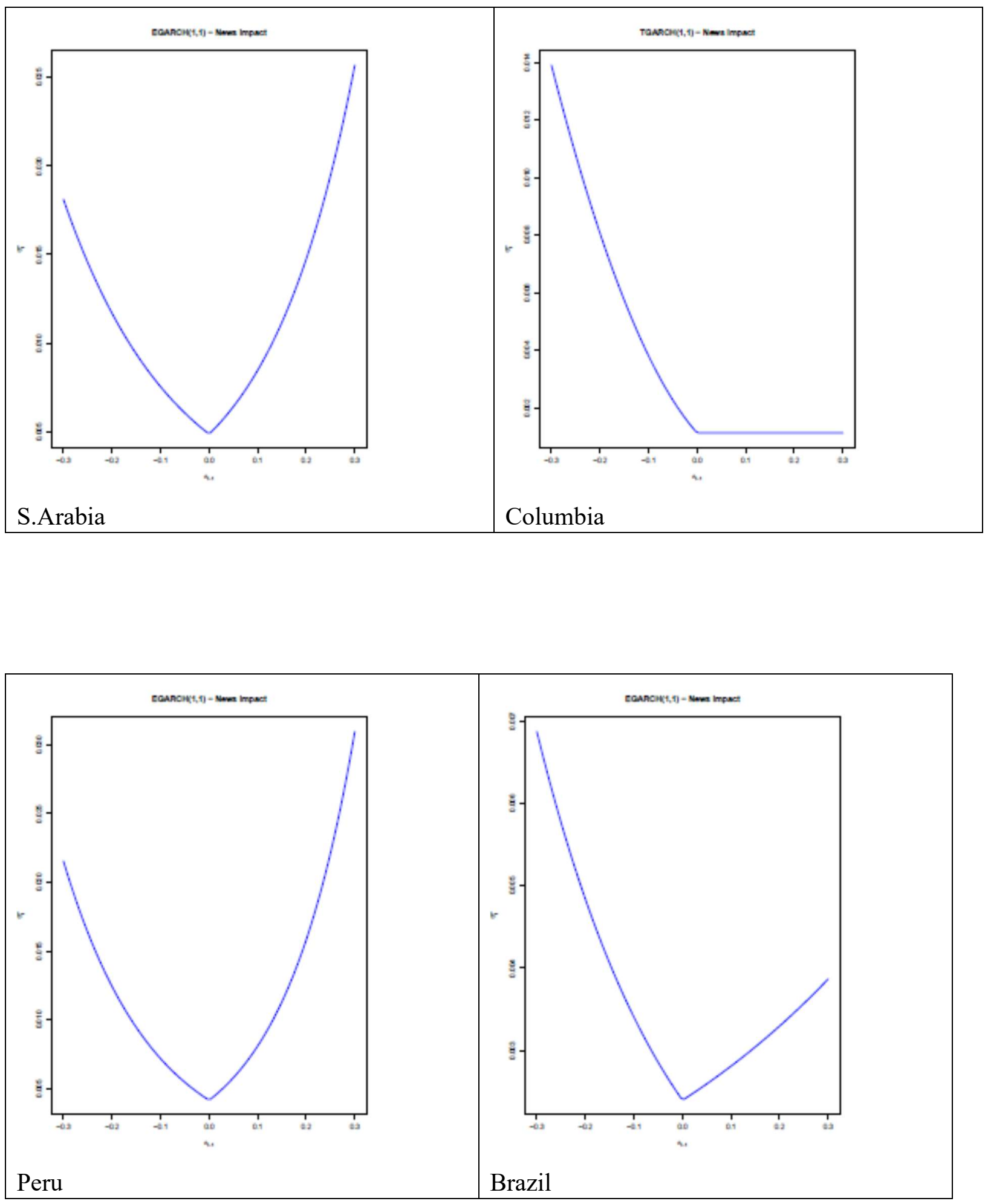


\section{Macrothink}

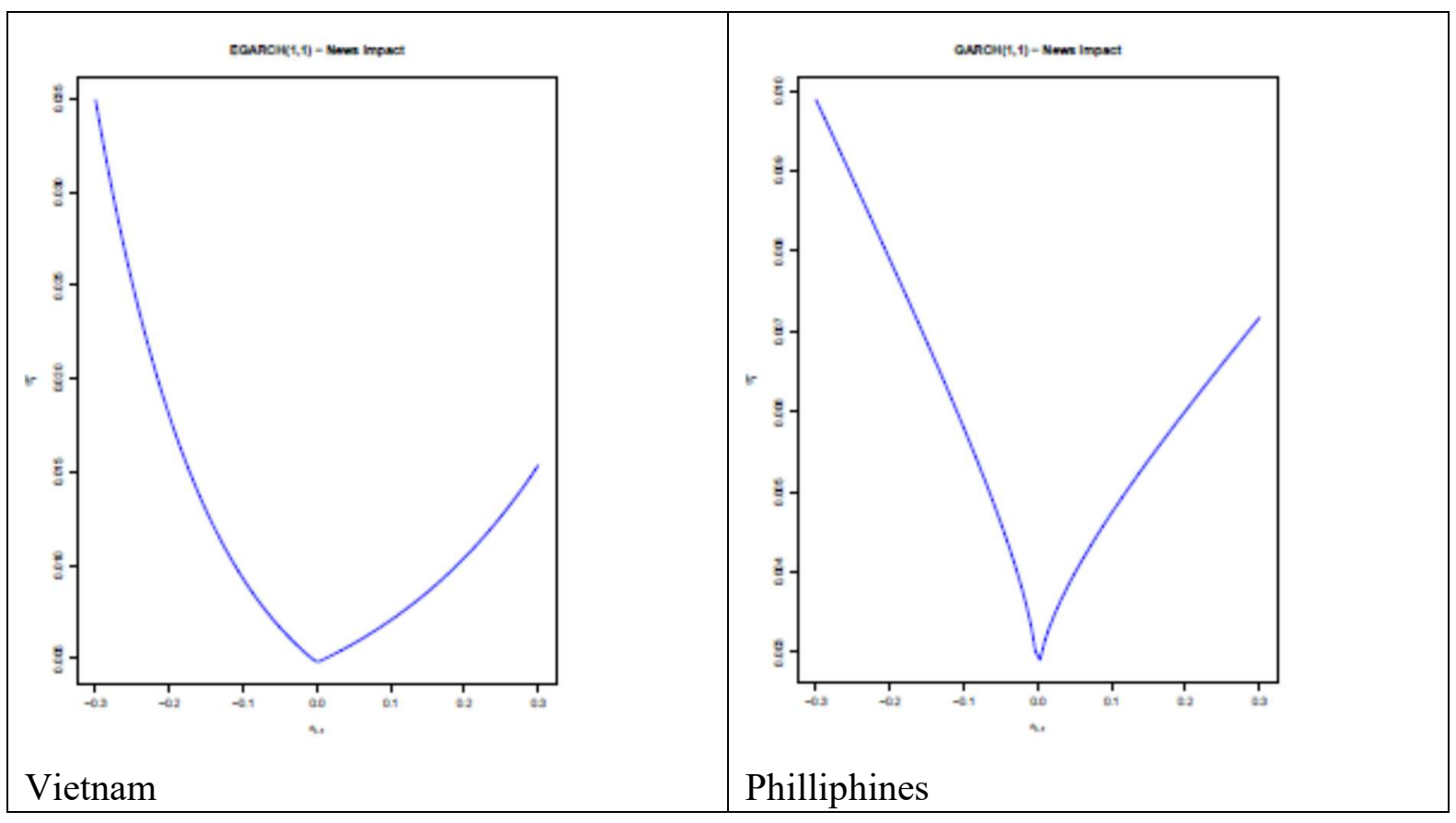

\section{Conclusion}

Assessment of leverage and investment decisions in firms in emerging economies is significant as numbers of investors are risk averse. This study attempts to model the volatility of stock market return in 14 selected OPEC countries which are termed as emerging economies by testing both the symmetric and asymmetric models. The monthly closing prices for ten years were extracted and modeled using three different GARCH models after verifying the unit root test and ARCH effects. The study further conducted empirical analysis on ARCH and GARCH models to investigate volatility characteristics through the period Jan 2008 to Dec 2017, to determine volatility clustering, leptokurtic distribution and leverage effect.

To capture the symmetry effect in the stock markets, both the ARCH and GARCH $(1,1)$ model is employed. The primary empirical findings of the stock return data is far from normality and showed existence of conditional heteroscedacity or volatility clustering. Further the study found evidence of leptokurtosis, long memory, fat tailed and persistence of volatility. All these are consistent with previous research. GARCH $(1,1)$ results indicate persistence for all the countries studied which signifies that the current shock persists indefinitely in conditioning the future variance.

With respect to detecting the asymmetric effect in the data, $\operatorname{EGARCH}(1,1)$ and TGARCH $(1,1)$ were applied, in order to investigate the various effects of good and bad news on the future volatility of the selected data. In EGARCH model, none of the countries indicated negative and significant gamma and there was absence of support of leverage effects. Thus the stock return is considered volatile. The gamma coefficient indicated that Iran had the maximum impact on volatility due to negative information.

The study also verifies whether incorporating asymmetric response of volatility to positive and negative shocks changes the conclusions obtained from the symmetric GARCH models. In order to corroborate the best fitted model from the models applied, Akaike Information 
Criterion (AIC), Log Likelihood, and Shwarz Information Criterion(SIC) were used. Findings indicate that TGARCH model was found out to be the best fitted model for all the emerging economies considered in the study based on the highest Log Likelihood with least AIC and SIC criterion. As per the TGARCH output, the asymmetric effect was captured and Leverage effects were found in Peru, Iran, South Africa and Colombia, implying that negative shocks stimulates a higher raise in volatility than the positive shocks.

Tests for asymmetries in volatility indicate a size effect of news, which is stronger for bad news than good news in case of countries where leverage was captured by use of sign-bias tests. The main intention of using NIC curves was to look for incidence of leverage effects, influencing volatility by previous good or bad news. The return series were used to compute News Impact Curves (NIC), which pointed out the inadequacy of using GARCH in the presence of asymmetric volatility effects, which treats all volatility equally. The NIC for the asymmetric models indicate that bad news have more impact on volatility than good news in Peru, Iran, South Africa, Colombia and Egypt. Iran has had a turbulent period since 2010 with successive negative events of high inflation, monetary / credit policy measures taken by the government to combat it and finally the sanctions imposed by European Union and the USA leading to depreciation of currency and thus adversely impacting the stock Market. In case of South Africa, the markets witnessed volatility since 2013 when $60 \%$ of the domestic flows were routed to offshore funds and was followed by political rout when they had three finance ministers in a week which distressed the investors' confidence. Though, Colombian stock market has at all times traded at a premium to its worldwide emerging market peers, the relative prices of Colombia to global emerging markets have always been extremely volatile. During the period of global financial crisis in 2008 Colombian market traded at $35 \%$ discount to GEM moving to $70 \%$ premium two months later. Such large swings echo the reliance of index on small number of companies and relative thin trading liquidity.

The upward trend of the NIC on the positive side of the shocks depicts the increasing confidence in the stock markets of Russia, Saudi Arabia and Vietnam. Saudi Arabia has seen uptrend in its stock market performance since 2014 when it opened it up for foreign investors. Though the country experienced lows due to major drop in oil prices following the global financial crisis, TASI lifted the benchmark by $38 \%$ since 2013. In case of Russia, the MICEX indices demonstrated intense vintages in 2008 and 2009. Later neither the economic sanctions on Russia nor did the period of Ukrainian crisis impact the indices in a major way. Only the MICEX financial index exhibited major losses and high volatility. Vietnam saw a series of positive events impacting their economy since the government scrapped the law limiting foreign investments and the modification of their securities law which lead to a boom of its stock market. Thus the results are in tune with international evidence of financial data exhibiting the phenomenon of volatility clustering, fat tailed distribution, persistence and asymmetrical effects.

\section{References}

Aboura, S. and Wagner, N. (2016). Extreme asymmetric volatility: Stress and aggregate asset prices. Journal of International Financial Markets, Institutions \& Money, 41, 47-59. https://doi.org/10.1016/j.intfin.2015.12.004 
Asgharian, H. (2016). Empirical Finance Lecture notes. Lund University. A taste of the efficient market hypothesis. Journal of Finance, 32, 663-682.

Akaike, H. (1973). A New Look at the Statistical Model Identification. IEEE Transactions on Automatic Control, 6(19),716-723.

Akpan, E. A., \& Moffat, I. U. (2015). ARCH Modeling of the Returns of First Bank of Nigeria. American Journal of Science and Industrial Research, 6(6), 131-140. https://doi.org/10.5251/ajsir.2015.6.6131.140

Akpan, E. A., Moffat, I. U., and Ekpo, N.B. (2016). ARMA -ARCH Modeling of the Returns of First Bank of Nigeria. European Scientific Journal. 12(8), 257-266. https://doi.org/10.19044/esj.2016.v12n18p257

Asteriou, D., \& Hall, S. G. (2007). Applied Econometrics. A Modern Approach. Publisher: Palgrave Macmillan.

Atoi, N. V. (2014). Testing Volatility in Nigerian Stock Market Using GARCH Models. $C B N$ Journal of Applied Statistics, 5(2).

Basu, S. (1977). Investment performance of common stocks in relation to their price-earnings ratios.

Bekaert, G., \& Wu, G. (2000). Asymmetric volatility and risk in equity markets. Review of Financial Studies, 13, 1-42. https://doi.org/10.1093/rfs/13.1.1

Box, G. E. P., Jenkins, G. M., \& Reinsel, G. C. (2008). Time Series Analysis: Forecasting and Control. (3rded.). New Jersey: Wiley and Sons, 47-89. https://doi.org/10.1002/9781118619193

Brockwell, P. J., \& Davis, R. A. (2002). Introduction to Time Series and Forecasting. (2nded.). Springer, 83 -219. https://doi.org/10.1007/0-387-21657-X_3

Campbell, J. A., Lo, A. W., \& Macinlay, A. C. (1998). The Econometrics of Financial markets. New Jersey: Princeton University Press.

Chan, K. C., and Chen, N. F. (1991). Structural and return characteristics of small and large firms. Journal of Finance, 46, 1467-1484. https://doi.org/10.1111/j.1540-6261.1991.tb04626.x

Cheung, J., \& Ng, L. (1992). Stock price dynamics Engle, R. F. (1982). Autoregressive Conditional Heteroskedasticity with Estimates of the Variance of United Kingdom Inflation. Econometrica, 50, 987-1007.

Emenike, K.O. (2010). Modeling Stock Returns Volatility in Nigeria using GARCH Models. Available at http://ijsp.ccsenet.org. International Journal of Statistics and Probability, 6(6), 2017.

Engle, R. F., \& Ng, V.K. (1993). Measuring and Testing the Impact of News on Volatility. Journal of Finance, 48(5),1749 -1778. https://doi.org/10.1111/j.1540-6261.1993.tb05127.x

Fama, E. F., \& French, K. R. (1992). Common risk factors in the returns on stocks and bonds. Journal of Financial Economics, 33, 3-56. https://doi.org/10.1016/0304-405X(93)90023-5 
Fama, E. F., \& MacBeth, J. D. (1973). Risk, Return and Equilibrium: Empirical tests. The Journal of Political Economy, 81(3), 607-636. https://doi.org/10.1086/260061

Hagerud, G. E. (1997). Specification Test for Asymmetric GARCH. Available atSwopec.hhs.se/hastef/papers/hastef0163.pdf. Extracted on 4 July, 2017.

Jensen, M. C., Black, F., \& Scholes, M. S. (1972). The capital asset pricing model: Some empirical results. New York: Preager.

Koller, T., Goedhart, M., \& Wessels, D. (2015). Valuation; Measuring and managing the value of companies. New Jersey: John Wiley \& Sons.

Scott, R. W. (2008). Institutions and organizations. Ideas and Interests (Third edition). Thousand Oaks: California: Sage publications Inc.

Sharpe, W. F. (1964). Capital asset prices: A theory of market equilibrium under conditions of risks. The Journal of Finance, 19, 425-442. 43

Shefrin, H. (2007). Behavioral corporate finance. New York: McGraw Hill.

Shou, S. (2014). Evaluating a simple trading strategy with dividend stocks. CMC Senior Theses. 806.

Su, Y., \& Chen, P. (2009). Asymmetric GARCH Value at Risk for QQQQ. Working paper.

Tsay, R. S. (2010). Analysis of Financial Time Series. ( $3^{\text {rd }}$ ed.). New York: John Wiley \& Sons Inc.97 -140. https://doi.org/10.1002/9780470644560

Ulbricht, N., \& Weiner, C. (2005). World scope meets Compustat: A comparison of financial databases. Working paper, 1-36. https://doi.org/10.2139/ssrn.871169

Voogd, J. J., \& Geschiere, T. (2015). Asymmetric volatility: Testing firm-specific factors as a cause for the "leverage effect" using GARCH-modeling. Lund. Master thesis.

Wang, J., \& Yang, M. (2009). Asymmetric volatility in the foreign exchange markets. Journal of International Financial Markets, Institutions and Money, 4, 597-615. https://doi.org/10.1016/j.intfin.2008.10.001

Wan-Ting, W. (2014). The P/E Ratio and Profitability. Journal of Business \& Economics Research, 12, 67-76. 